\title{
EL CONTROL JURISDICCIONAL DE LAS FACULTADES PRIVATIVAS DE LOS PODERES ESTATALES, EN LA DOCTRINA DE LA CORTE SUPREMA DE JUSTICIA DE LA NACIÓN ARGENTINA
}

\section{THE JURISDICTIONAL CONTROL OF THE PRI- VATE POWERS OF THE STATE POWERS, IN THE DOCTRINE OF THE SUPREME COURT OF JUSTICE OF THE ARGENTINE NATION}

RESUMEN:

El control jurisdiccional del ejercicio de las llamadas facultades privativas de los poderes del Estado, forma parte como un capítulo específico comprendido dentro del planteo general de las denominadas cuestiones no justiciables o cuestiones políticas.

Se realizara en la primera parte un análisis sobre la normatividad y arbitrio político, las cuestiones políticas y los presupuestos del acto estatal, la zona de reserva política, y ¿Cuándo procede o no, el control judicial?.

Luego se desarrollan las facultades privativas y las cuestiones políticas, con algunos pronunciamientos paradigmáticos de la Corte Suprema sobre la justiciabilidad de las facultades privativas, para llegar a las conclusiones finales.

ABSTRACT

The jurisdictional control of the exercise of the so-called exclusive powers of the powers of the State, forms part as a specific chapter included in the general statement of the so-called non-justiciable issues or political issues.

In the first part, an analysis will be carried out on the normativity and political discretion, the political issues and the budgets of the state act, the political reserve zone, and when does the judicial control

1 El presente trabajo con algunas modificaciones, es similar al presentado para su publicación en los Anales de la Academia Nacional de Derecho de Córdoba 2019. Profesor Emérito de las Universidades Blas Pascal y Nacional de Córdoba. Presidente Honorario de la Asociación Argentina de Derecho Constitucional. Miembro de la Academia Nacional de Derecho de Córdoba. 
proceed or not?

Then the private powers and political issues are developed, with some paradigmatic pronouncements of the Supreme Court on the justiciability of the private powers, to reach the final conclusions.

PALABRAS CLAVE: El control jurisdiccional - Constitución Nacional - Facultades Privativas - Cuestiones políticas no justiciable - Corte Suprema de Justicia de la Nación.

KEY WORDS: Jurisdictional control - National Constitution - Private Powers Non-justiciable political issues - Court Supreme Justice of the Nation.

\section{A MANERA DE PROEMIO}

\section{Lo jurídico y lo político; el mundo jurídico y el mundo político}

El tema referido al control jurisdiccional del ejercicio de las llamadas facultades privativas de los poderes del Estado, forma parte como un capítulo específico comprendido dentro del planteo general de las denominadas cuestiones no justiciables o cuestiones políticas. Es por ello que de modo previo al estudio de aquél, sea necesario señalar que en el trasfondo conceptual de las "cuestiones políticas", surge con decisiva necesidad, la caracterización de lo político y de lo jurídico. Con Alberto A. Spota ${ }^{2}$ quien ha analizado tan agudamente las relaciones de "lo jurídico" con "lo político", podemos expresar que el ordenamiento jurídico establece normativamente el señalamiento de una conducta debida y enuncia una sanción para el supuesto de incumplimiento de esa conducta, de forma tal que la coacción efectivizada objetivamente, se constituye en elemento esencial de "lo jurídico".

Desde otra perspectiva, en "lo político" campea el arbitrio, como capacidad para decidirse libremente entre opciones que han sido dadas o para crear nuevas opciones, produciendo respuestas eficaces en la superación de los desafíos o incitaciones recibidas por el poder político.En este sentido recurrimos a la reconocida sabiduría del eminente politólogo español Luis Sánchez Agesta ${ }^{3}$, quien con la claridad y profundidad que lo caracteriza, nos señala que la acción política es actividad social no sujeta a normas jurídicas, esto es, actividad no normalizada jurídicamente. En la vida social hay actos ordenados, cuya realización y eficacia están previstos por una norma jurídica y que se cumplen de acuerdo con lo que esa norma prescribe. La acción política, en cambio, no es regular, cumplida de acuerdo con una regla, sino acción creadora, impulso de lo nuevo y de lo imprevisto. Cuando discurre en el cuadro de una norma, esta norma contiene un amplísimo margen de discrecionalidad en cuanto a la realización o no del acto, su tiempo, sus contenidos.

Atendamos ahora a lo que con notable agudeza el profesor alemán Gerhard Leibholz, nos señala al manifestar que la jurisdicción constitucional que ejerce el Tribunal Constitucional Federal alemán, penetra dentro del dominio de lo político, dado que en contraposición a la jurisdicción civil, penal o administrativa, la constitucional es competente para una clase especial de conflictos jurídicos: los conflictos jurídicos sobre materias políticas, en los que el elemento político, bajo ropajes jurídicos, se convierte en el objeto principal de la decisión judicial. Uno de los básicos principios de la jurisdicción constitu-

2 "Lo político, lo jurídico, el derecho y el poder constituyente", Plus Ultra, Buenos Aires 1975, pp. 24/25 y 86 y concordantes.

3 "Principios de Teoría Política”, Editora Nacional, Madrid 1972, p. 59. 
cional es que los litigios y controversias de índole y planteamiento puramente políticos (distintos de los conflictos de contenido político y planteamiento jurídico) estén excluidos de la jurisdicción. Afirma que las controversias políticas puras (para nosotros "no justiciables") en contraposición a los litigios jurídicos sobre materias políticas (para nosotros "justiciables"), son conflictos que no pueden ser resueltos por la mera aplicación de normas jurídicas. ${ }^{4}$

Aún sin entrar en hondas especulaciones sobre el complejo tema de lo jurídico y lo político, inviables en el presente estudio, lo cierto es que a nadie se le escapa en una aproximación básica pero correcta del tema, que la distinción entre lo político y lo jurídico aparece como manifiesta a poco que se repare que una cosa es el ámbito de la política y otra el ámbito de lo jurídico dentro del cual debe desenvolverse toda la actividad estatal en un Estado de Derecho. Parafraseando a Ortega y Gasset que nos decía que "el derecho es realidad social, pero no es toda la realidad social", nosotros podemos afirmar "que el derecho es realidad política, pero no es toda la realidad política".

A esta altura de las reflexiones que venimos desarrollando, consideramos de trascendental importancia afirmar que en manera alguna dudamos que toda actividad humana, ya sea personal, social o política, se mueve siempre dentro del gran marco que le fija el derecho, a través de mandamientos, prohibiciones y permisiones. Dicho de otro modo, indiscutiblemente toda conducta o comportamiento en dichos ámbitos, siempre estarán enmarcados por un orden jurídico, ya sea preciso y minucioso o amplio o espacioso que, así como le asegura el legal y razonable ejercicio de sus legítimos derechos y potestades, así también le fija los límites a las diversas dimensiones de sus actuaciones, pues si bien es cierto que invariablemente en ellos habrá aspectos discrecionales y de libre arbitrio, también es cierto que en manera alguna podrán ejercerse ilimitada o absolutamente. ${ }^{5}$

Atendamos la crítica que formula el recordado maestro Germán Bidart Campos cuando señala que la retracción del control judicial en las cuestiones políticas, importa una construcción defectuosa que tiene vigencia en nuestra constitución material por obra del derecho judicial derivado de la Corte Suprema. Para él, el no juzgamiento de las cuestiones políticas viola el derecho a la jurisdicción de la parte afectada, en cuanto le impide obtener una sentencia que resuelva la cuestión política propuesta o comprometida en la causa; asimismo implica también declinar el ejercicio pleno de la función de administrar justicia, impidiendo remediar la eventual inconstitucionalidad de las actividades que, por configurar cuestiones políticas, quedan exentas del control judicial, con lo cual la responsabilidad del Estado se esfuma pese a la infracción constitucional. ${ }^{\circ}$

Sabido es que, no obstante que el orden jurídico estatal nutre toda su validez de la supremacía de propia Constitución como Ley Fundamental que realiza el reparto de las competencias supremas del Estado y enmarca todas las manifestaciones de la actividad política, no podemos ignorar que diversos momentos del desarrollo de dicha actividad política, necesariamente se nutren de comportamientos, libertades y elecciones, donde lo jurídico deja amplios espacios a la decisión de las múltiples opciones válidas para el logro de objetivos de bien común.

Ello así, sostenemos que pretender encerrar o "encorsetar" la vasta y compleja dinámica realidad política, en un hermético sistema jurídico que todo lo contemple y todo lo regule, y en consecuencia, donde todos sus aspectos y contenidos puedan ser compulsados y controlados desde una perspectiva normativa, es una posición utópicamente errónea

\footnotetext{
4 Problemas Fundamentales de la Democracia Moderna”, Instituto de Estudios Políticos de Madrid, Colección Civitas, 1971, pp. 149/154.

5 HARO, Ricardo, Control de Constitucionalidad, Editorial Zavalía, Buenos Aires, 2008, p. 218

6 BIDART CAMPOS, Germán, Tratado Elemental de Derecho Constitucional Argentino, Ediar, Buenos Aires 1993, pp. 520/21.
} 
que por ignorar la diferenciación entre lo jurídico y lo político, nos conduce necesariamente a conclusiones desacertadas.

\section{Normatividad y arbitrio político}

Conforme con la diferenciación hasta aquí expuesta, resulta indispensable distinguir las dos perspectivas que manifiesta todo acto estatal en el ejercicio de las atribuciones de los órganos del poder, a saber: a) La perspectiva normativa, reglada o estrictamente jurídica; b) La perspectiva del arbitrio, de lo discrecional o estrictamente político.

Y esto es así, porque si bien es cierto que lo jurídico siempre trasunta una dimensión política que lo inspira, también lo es que lo político -como expresión de la voluntad estataltiende a implementarse a través del derecho y siempre dentro de su marco. De allí que en los actos estatales advirtamos por una parte, la perspectiva jurídica en que predominará un contenido estrictamente jurídico; por otra, la perspectiva política, integrada por los ingredientes políticos necesarios en el ejercicio de toda potestad gubernamental; $y$, finalmente, aquéllos actos en que se conjuguen equilibradamente ambos contenidos: la normatividad jurídica y el arbitrio político. ${ }^{7}$

En conclusión, podemos afirmar que, en la consideración de la legislación y, en particular, en toda norma jurídica, encontraremos por una parte, contenidos juridizados que deben ser debidamente cumplimentados, y por otra, posibilidades políticas que se abren a la libre meditación y elección del gobernante, similarmente como en el Derecho Administrativo nos encontramos con la paradigmática distinción de los aspectos reglados y los aspectos discrecionales del acto administrativo.

\section{Las cuestiones políticas y los presupuestos del acto estatal}

La formalización jurídica de todo acto estatal presupone:

a) La constitución de un órgano que lo emita; b) La competencia o atribuciones legales de dicho órgano; c) El procedimiento que la $\mathrm{CN}$ o la ley establezcan para el ejercicio de su competencia; d) Las situaciones fácticas y requirentes de la realidad social que exigen de la decisión y acción gubernamental, soluciones a los problemas de la convivencia. Ello así, es indudable que la normatividad jurídica primará en los tres primeros presupuestos (constitución del órgano, su competencia y el procedimiento). Por el contrario, es en el cuarto presupuesto (decisión y acción gubernamental ante situaciones fácticas), en el que sienta sus reales con mayor virtualidad, el arbitrio, la visión y la imaginación política, evaluando los problemas y tomando las decisiones que se estimen más eficientes.

\footnotetext{
7 HARO, Ricardo, ob. cit. P. 218/219

A fin de complementar lo expuesto, puede consultarse la doctrina de los constitucionalistas argentinos, que en su mayoría afirma una actitud favorable hacia una mayor justiciabilidad de las tradicionalmente llamadas "cuestiones políticas" a partir de una posición moderada basada en la convicción de que siempre existirán algunas "no justiciables". En cambio, otros juristas, los menos, se han inclinado hacia una categórica afirmación de la "plena justiciabilidad de todas las llamadas "cuestiones políticas". En tal sentido podemos señalar: Joaquín V. Gonzalez, "Manual de la Constitución Argentina", Edit. Estrada, 1951, pág. 321; Juan A. González Calderón, "Curso de Derecho Constitucional", Edit. Kraft 1960, pág. 106; Carlos María Bidegain, "Cuadernos de Derecho Constitucional", Buenos Aires, 1975, T. I - 127 a 139. En similar sentido: Legón Faustino J., en "Tratado de Derecho Político General", Ediar, 1961, T. II - 367; Segundo V. Linares Quintana, "Derecho Constitucional e Instituciones Políticas", Plus Ultra 1981, T. I - 561/93; Cesar Enrique Romero "Derecho Constitucional", Edit. Zavalía, 1975, pág. 334; propulsor vigoroso de la plena justiciabilidad de las "cuestiones políticas", Germán Bidart Campos, "Derecho Constitucional del Poder", Ediar 1967, T. II - 333/42. Esta posición fue defendida por el Dr. Luis M. Boffi Boggero siendo Ministro de la Corte Suprema de Justicia de la Nación (F. 243-260; 248-71; 252-54; 254-47; 261-105; entre muchos otros); Miguel S. Marienhoff, "Tratado de Derecho Administrativo", Abeledo Perrot, 1966, T. II - 755 y ss.; Jorge R. Vanossi, "Teoría Constitucional", Depalma 1976, T.II - 177/211; Néstor P. Sagües, "Recurso Extraordinario", Depalma, 1984, T. I - 147/51, y en "Mundo Jurídico y Mundo Político”, Ediciones Depalma, Bs. Aires 1978, pág. 174; Humberto Quiroga Lavié, "Derecho Constitucional", Cooperadora de Derecho, Buenos Aires, págs. 491/94; Pablo A. Ramella, "Derecho Constitucional", Depalma, 1982, págs. 219/223; Alberto B. Bianchi, "Control de Constitucionalidad", Edit. Ábaco, Bs. As. 1992, págs. 381/82; Miguel Angel Ekmekdjian, "Tratado de Derecho Constitucional", Depalma, Bs. As. 1995, T. III, págs. 334/36; a) Alberto Ricardo Dalla Via, "Manual de Derecho Constitucional", LexisNexis, Buenos Aires, 2004; b) Adolfo Gabino Ziulú, en "Derecho Constitucional", Depalma, Bs. As., 1997, t.I, págs. 113/16; c) Mario A. R. Midón, en "Manual de Derecho Constitucional Argentino", Edit. La Ley, Buenos Aires, 2004.
} 


\section{La zona de reserva política}

Como hemos sostenido en anteriores oportunidades, nosotros entendemos que la discrecionalidad y el arbitrio propio de los actos estatales, no es otra cosa que un margen o ámbito de libre disposición, dentro del marco jurídico y según pautas axiológicas que hacen a la necesidad, oportunidad, conveniencia y eficacia de la decisión que se vaya a tomar. La valoración de estas pautas - de suma importancia- constituyen una zona de reserva política en la cual, el gobernante buscará prudentemente, la mejor solución entre muchas alternativas. Reiteramos: Esta libre disposición dentro del marco normativo, es lo no justiciable, porque es el aspecto verdaderamente "político" en la actuación del órgano.

Lo que escapa a la competencia del Poder Judicial, compartimos con Segundo V. Linares Quintana, es exclusivamente la revisión del juicio de valor de sustancia política, pero en manera alguna las proyecciones del acto político sobre los derechos constitucionales, cuyo amparo es misión específica de los tribunales de justicia. ${ }^{8}$

Por lo tanto, es preciso tener muy presente que la "cuestión política" no se tipifica por pertenecer al ámbito político o por la finalidad política que persiga, sino que la cuestión debe ser en sí misma, esencial, objetiva y exclusivamente política, sin contenido ni configuración jurídica precisamente prescripta.

\section{5. ¿Cuándo procede o no, el control judicial?}

El control judicial es básicamente un control de juridicidad constitucional y legal, por el cual los tribunales verifican si en el caso sub-examine, se han cumplido o no las prescripciones jurídicas, ya sea en las conductas que impone, como en las que prohíbe y en las que permite.

De allí que para nosotros constituya el meollo del asunto, poder afirmar que existe justiciabilidad, en todo aquello en que los principios y las normas constitucionales o legales, han regulado de tal forma la cuestión sub-examine, que en menor o en mayor medida, pueda realizarse el juicio cierto, concreto y objetivo, que permita detectar y declarar alguna violación a la regulación constitucional o legal, mediante un adecuado juicio comparativo de compatibilidad.

Dicho de otra forma más concisa y sustancial, nosotros entendemos que existe justiciabilidad respecto de todo el ámbito de lo normado y en toda la hondura de lo normado, pero nunca más allá de lo normado.

En cambio, entendemos que no procede la justiciabilidad:

a) En lo relativo a la apreciación o juicio sobre la existencia o no de una situación fáctica, que si bien puede estar prevista en la constitución o en la ley, no posee una configuración o forma jurídica lo suficientemente precisa y determinada, razón por la cual su existencia queda librada fundamentalmente a la valoración política (v.g. la conmoción interior para declarar el estado de sitio (art. $23 \mathrm{CN}$ ), o la utilidad pública para la expropiación (art. $17 \mathrm{CN}$ ).

b) Igualmente estimamos justiciable, el ejercicio de facultades privativas por parte de cualquiera de los poderes, si han respetado las normas jurídicas que lo rigen, tanto en el debido proceso sustancial, es decir, en cuanto al contenido normativo, como en el debido proceso formal o adjetivo, es decir, cuando se han dado cumplimiento a las normas que regulan el órgano y el procedimiento para actuar esa facultad privativa.

c) Finalmente tampoco aceptamos la justiciabilidad en todos los casos en que los poderes estatales, frente a concretas situaciones (económicas, culturales, sociales, etc),

8 LINARES QUINTANA, Segundo V., "Derecho Constitucional e Instituciones Políticas", Abeledo Perrot, Buenos Aires, 1970 , t.1 p. 632. 

EN LA DOCTRINA DE LA CORTE SUPREMA DE JUSTICIA DE LA NACIÓN ARGENTINA

deban realizar un juicio de prudente valoración política sobre la necesidad, la oportunidad, la conveniencia, el mérito o la eficacia de las respuestas que deben darse a dicha demanda. Todo ello sin perjuicio, lógicamente, de la justiciabilidad en caso que trascendiendo esas coordenadas, el órgano competente haya actuado en forma manifiestamente irrazonable o inicua, en los actos concretos de ejecución que afecten los derechos y garantías constitucionales.

\section{Mayor justiciabilidad y el gobierno de los jueces}

A pesar del progresivo avance de la doctrina judicial respecto de la justiciabilidad de las "cuestiones políticas", la CS ha sido cautelosa con la adopción de posiciones extremas, pues no sin razón, ha sostenido que el ejercicio incontrolado de la función jurisdiccional irrumpiendo en el ámbito de las atribuciones reservadas a los otros poderes, constituye una anomalía constitucional axiológica, caracterizable como pretensión de "gobierno de los jueces", según la peyorativa expresión acuñada por la doctrina francesa. La politización de la función judicial que trae aparejada la decisión por aquélla de puntos esencialmente injusticiables por su naturaleza preponderantemente "política", puede engendrar además de una grave desviación de justicia, un ejercicio distorsionado de la función jurisdiccional.

Creemos poder compartir plenamente la sustancia de esta doctrina, pues según lo venimos afirmando, la justiciabilidad debe llegar hasta donde llega toda la amplitud y las implicancias del bloque de juridicidad (constitucional y legal). Es allí donde el Poder Judicial ejerce su trascendental función moderadora en el sistema constitucional, moderación que debe lograr tanto: a) Entre el poder constituyente y los poderes constituidos b) Entre los diversos poderes del gobierno federal; c) Entre el gobierno federal y los gobiernos de provincias; y d) Entre el Estado y la Sociedad.

Pero los tribunales con la CS a la cabeza, no pueden caer en un desmesurado "activismo judicial", impulsados por un errónea pretensión de sentirse y considerarse los custodios exclusivos de la $\mathrm{CN}$ e inmiscuyéndose en tópicos inherentes a una perspectiva exclusiva o puramente política, propios de los departamentos políticos. Sería lamentable que ejerciendo el control de constitucionalidad, los jueces de todas las instancias con la CS a la cabeza, pretendieran erigirse en los supremos y finales contralores de todas las actividades estatales, sin advertir que no toda actividad estatal es controlable judicialmente en las diversas facetas o aspectos que la integran.

Ello no nos impide sostener con igual énfasis que siendo la CS custodio e intérprete final de la Carta Magna y del reparto de las competencias supremas del Estado que realiza, cumple dicha función desde su propia e indelegable perspectiva jurídico-política, ejerciendo el control de constitucionalidad de los actos estatales, control que si bien es jurídico, posee vastas y profundas connotaciones políticas.

El Poder Judicial a través de este control, ejerce una de las funciones relevantes como poder del Estado, pues no es dable concebir que sólo sea político el poder de elaborar la ley (le pouvoir d'etablir), y no lo sea el poder de enervarla por inconstitucional, marginándola del orden jurídico válido (le pouvoir d'empêcher). ${ }^{10}$

\section{A modo de recapitulación}

1) Nos enrolamos decididamente en la corriente que propugna un avance prudente pero vigoroso de la justiciabilidad de las llamadas "cuestiones políticas", según las pautas precedentemente establecidas en este trabajo.

9 HARO, Ricardo, ob. cit. p. 222.

10 HARO, Ricardo, ob. cit pp.. 223/24. 
2) Si bien debe atenderse a la "naturaleza" o al "ámbito político", o a los "fines políticos" del caso, lo realmente definitorio es que una cuestión es justiciable, en todas las implicancias que afecten el "bloque de juridicidad", los principios y la normatividad constitucional, legalo reglamentaria. Allí donde penetra la juridicidad, debe penetrar la revisibilidad jurisdiccional.

3) Dado que en cualquier acto estatal siempre habrá ámbitos normados y otros librados al arbitrio político (zonas regladas y otras discrecionales), más que de "cuestiones políticas", creemos necesario hablar de "aspectos políticos" de las atribuciones ejercidas por los órganos estatales. Siempre habrá un margen, amplio o pequeño para el arbitrio político, que se sustenta en un plano de libertad opcional dentro de un marco legal permisivo. De allí que -y esto es de trascendental importancia- la función judicial sea secundum legem, mientras que la función propiamente política, sea secundum arbitrium.

4) Deben los Tribunales Federales ir morigerando lo que se ha dado en llamar la "autorrestricción" o "self restraint". Es preciso que la CS asuma el responsable compromiso institucional que le compete como cabeza de Poder dentro del Estado, evitando abandonar espacios competenciales, que en muchas oportunidades serán ocupados por la arbitrariedad, ante la ausencia de un correcto control jurisdiccional, garantía última de un verdadero Estado de Derecho.

5) Descartamos de plano la politización del Poder Judicial que significa el procurar la plena justiciabilidad de todos los actos estatales y descargando en los jueces, problemas y controversias que exorbitan la naturaleza de su función judicial, en una equivocada visión que pretende constituir a los magistrados, en la última instancia que el sistema político ofrece para la solución de todos los conflictos.

\section{LAS FACULTADES PRIVATIVAS Y SU JUDICIABILIDAD}

\section{a. Las facultades privativas y las cuestiones políticas}

Pasando ahora al segundo apartado de nuestra exposición, cabe señalar que según una inveterada doctrina de la Corte Suprema de Justicia de la Nación (CS), escapa a la competencia del Poder Judicial (PJ), controlar el modo como los poderes políticos ejercitan las facultades que la Constitución Nacional (CN) les ha otorgado privativamente, las generalmente llamadas facultades privativas. Esta expresión la consideramos un estándar judicial, que por su falta de plena precisión, puede llegar a ser usado como "fórmulas de goma" en la expresión de Gény.

Para una mayor eficiencia de la doctrina de la división y equilibrio de los poderes, sabido es que existen atribuciones que si bien por un lado, tienden a afianzar la independencia o separación de los diversos Departamentos del Gobierno, por otro las hay que procuran lograr el equilibrio de los poderes, mediante la colaboración y el contro/ entre ellos. Esto implica evidentemente la existencia de facultades privativas en los Departamentos del Estado, pero de ningún modo ello significa que necesariamente pueda surgir de su naturaleza "privativa", lisa y llanamente, la irrevisibilidad judicial, pues presentar una simetría entre "facultades privativas" y "facultades no justiciables", no sólo es errónea, sino que constituye un expediente fácil para acentuar un Poder Judicial más encerrado, "autista", compartimentado y autorrestringido (self-restraint).

Si aceptásemos la errónea simetría que señalamos, congruentemente tendríamos que aceptar que "facultades privativas" tan específicas como v.g. la sanción de una ley por el Congreso, o el veto de un proyecto de ley o el dictado de un decreto reglamentario por el Poder Ejecutivo, o igualmente las sentencias del Poder Judicial, marginarían por esa sola circunstancia el control jurisdiccional, aún cuando pudieran ser abiertamente 

EN LA DOCTRINA DE LA CORTE SUPREMA DE JUSTICIA DE LA NACIÓN ARGENTINA

violatorias al orden constitucional o legal, todo lo cual es a todas luces inaceptable y manifiestamente aberrante.

Nosotros creemos que más que de "facultades privativas" de los poderes políticos, es preciso hablar de un "juicio o valoración privativos" que esos poderes deben realizar sobre la configuración de los supuestos que hagan procedente el ejercicio de las atribuciones que les otorga la CN (mérito, oportunidad, conveniencia, etc), juicio que lógicamente no es justiciable.

Por lo tanto, las llamadas facultades privativas, serán susceptibles de control jurisdiccional, toda vez que en su ejercicio afecten formal o sustancialmente el "debido proceso constitucional o legal", pues es inaceptable desde todo punto de vista, que existan "facultades privativas" en los poderes del Estado que, por su calidad de tales, no sólo puedan ser ejercidas al margen de los parámetros que hacen a su constitucionalidad, sino que además pretendan evadir el control de constitucionalidad jurisdiccional, esencial a la vigencia de la supremacía constitucional.

De aceptar la paridad entre facultades privativas y facultades no judiciables, nos llevaría a tener que "sacralizar" y admitir situaciones realmente irritantes en un Estado de Derecho, pues es a todas luces indispensable recalcar que no se puede aceptar que haya facultades privativas que autoricen la violación de la legalidad constitucional,. En cambio, en el ejercicio de dichas facultades privativas, existen juicios privativos que hacen al ámbito exclusivamente discrecional de su actuación en el marco de la superlegalidad constitucional.

El principio de la separación de los poderes y el necesario auto-respeto por parte de los tribunales de los límites constitucionales y legales de su competencia, impone que en el ámbito de las facultades que le son privativas con arreglo a lo prescripto por la CN, la función jurisdiccional de los jueces no alcance al modo de ejercicio de tales atribuciones, puesto que si así no fuere, se haría manifiesta la invasión del campo de las potestades propias de las demás autoridades de la Nación. En tal sentido es de tener muy presente que el alto Tribunal ha sostenido: Esta Corte, incluso al ejercer el elevado control de constitucionalidad, debe imponerse la mayor mesura, mostrándose tan celosa en el uso de las facultades que le son propias, cuanto en el respeto de las que la CN asigna, con carácter privativo, a los otros poderes federales y a las autoridades provinciales (Fallos: 263-265, Partido Justicialista, 1965; en igual sentido, Fallos: 32-120; 170-246; 210.1095; 242-73; 254-43; 313-63 de 1990; 321-3236, de 1998, entre otros).

\section{b. Tesis restrictiva de la Corte Suprema de Justicia de la Nación}

En éste tan polémico tema, las facultades privativas han sido invocadas permanentemente en su momento por la CS -en nuestro criterio erróneamente- para fundamentar la irrevisibilidad de las mismas en numerosos antecedentes jurisprudenciales. Sólo hemos escogido el caso "Partido Justicialista" de 1965 (Fallos: 263-265), pues allí encontramos una apretada síntesis de la pertinente doctrina judicial negatoria. En efecto, recordando la "regla elemental de nuestro derecho público" sentada en el caso "Cullen v. Llerena" (Fallos: 53-420), la CS nos recuerda que las facultades que la CN ha establecido como propias y exclusivas de los otros poderes, son privativas de éstos y no pueden ser revisadas o interferidas por los magistrados judiciales, en cuanto a la forma de su ejercicio, y asimismo nos recuerda que "En tanto no se discuta la existencia de las atribuciones propias de otro poder, la revisión del acierto de sus actos no incumbe a los jueces" ("Ávila Posse" de 1962, Fallos: 254-43).

Esta Corte, incluso al ejercer el elevado control de constitucionalidad, debe imponerse la mayor mesura, mostrándose tan celosa en el uso de las facultades que le son propias, 
cuanto en el respeto de las que la CN asigna, con carácter privativo, a los otros poderes federales y a las autoridades provinciales (en igual sentido, Fallos: 32-120; 170-246). Conforme a ello, en 1990 la CS explicitó aún más este principio restrictivo al expresar que no puede admitirse que el órgano jurisdiccional obligue al Poder Ejecutivo a la remisión al Senado de un pliego para la promoción de un diplomático, ya que se trata de un acto político de dicho poder, a quien la $\mathrm{CN}$ ha atribuido en forma exclusiva y excluyente su ejercicio ("Colombo Murúa", Fallos: 313-63).

\section{c. Avances hacia la justiciabilidad}

Un moderado pero nítido avance en la justiciabilidad, se produjo en la sentencia del 13 de mayo de 1993, en la causa "Apoderados y Electores de la Alianza Frente de la Esperanza" (Fallos: 316-972), cuando la CS con notable claridad conceptual, afirmó que "es inherente a la función del Tribunal ante el cual se ha planteado una controversia referente al ejercicio de facultades privativas de otros poderes, interpretar las normas que las confieren para determinar su alcance, sin que tal tema constituya una "cuestión política" inmune al ejercicio de la jurisdicción. Decidir si un asunto ha sido conferido a otro Poder del Estado o si ha habido excesos en su ejercicio, es una delicada tarea de interpretación constitucional y una responsabilidad de la Corte, como último intérprete de la Constitución" (En similar sentido, Fallos: 321-3236 de 1998).

En el caso "Pelaez" de 1995 (Fallos: 318-1967), la CS consideró justiciable por ser de aplicación la Ley de Habeas Corpus 23.098, la causa en que se debía esclarecer las facultades del Senado para arrestar a una persona. Coincidentemente estimó que si se ha invocado ante el Poder Judicial la protección de la libertad ambulatoria, que se vería cercenada por una orden de arresto del Senado, se configura una "causa" y entonces, no hay otro poder por encima del de la CS para resolver acerca de la existencia y los límites de las atribuciones constitucionales otorgadas a los departamentos Legislativo, Ejecutivo y Judicial, y del deslinde de atribuciones de éstos entre sí y con respecto a los de las provincias.

Ratificando a contrario sensu de la precedente doctrina, cabe recordar el caso "Polino y otro" de 1994 (Fallos: 317-341), en el que se declaró improcedente el recurso extraordinario interpuesto en contra del rechazo de la acción de amparo incoada por Héctor $\mathrm{T}$. Polino y Alfredo P. Bravo, en su carácter de ciudadanos y diputados nacionales, a fin de que se declare la nulidad del proceso legislativo de la ley 24.309 que autorizó al P.E. a convocar al pueblo para elegir convencionales que reformarían la CN. Sostuvo la CS reseñadamente, que la atribución de declarar la invalidez constitucional de los actos de los otros poderes reconocida a los tribunales federales, ha sido equilibrada poniendo como límite infranqueable la necesidad de un "caso concreto" en el que se persigue la determinación de derechos debatidos entre partes adversas, cuya titularidad alegan quienes los demandan. Esto es así, dado que el fin y las consecuencias del control encomendado a la justicia sobre las actividades ejecutiva y legislativa, requieren que este requisito de un "caso" o "controversia judicial" sea observado rigurosamente para la preservación del principio de la división de los poderes.

\section{d. ¿Cuándo procede o no la justiciabilidad de una facultad privativa?}

Una declaración categórica en el tema expuso la CS al afirmar que "es inherente a las funciones de un tribunal judicial interpretar las normas que confieren las potestades que son privativas de los otros poderes para determinar su alcance, sin que tal tema constituya una "cuestión política" inmune al ejercicio de la jurisdicción" (entre numerosos, Fallos: 316-972; 321-3236; 322-2370). Ello no obstante, asimismo afirmó que "la función 
jurisdiccional de los jueces no debe alcanzar a interferir con el ejercicio de los actos que otros órganos del Estado han cumplido en el ámbito de las facultades que les son privativas y con arreglo a lo prescripto por la Constitución Nacional” (Fallos: 317-126). Quizás uno de las causas en que la CS reseñó los presupuestos fundamentales tanto para negar como para aceptar el control jurisdiccional, fue el caso "Prodelco" de 1998 en el que por unanimidad, se dejó sin efecto el fallo apelado que hizo lugar a la acción de amparo promovida por la Diputada Nacional Cristina Zuccardi y por la Asociación Protección del Consumidor "Prodelco" y declaró la inconstitucionalidad del art. 2 ㅇel Dto. 92/97 del P.E.N., por el cual se aprobaron las modificaciones a la Estructura General de Tarifas del Servicio Básico Telefónico.

Para ello, la CS expresó (Fallos: 321-1252), que desde antiguo se ha sostenido que la misión más delicada que compete al Poder Judicial es la de saber mantenerse dentro de la órbita de su jurisdicción, sin menoscabar las funciones que incumben a los otros poderes o jurisdicciones, toda vez que es el judicial el llamado para sostener la observancia de la $\mathrm{CN}$, y de ahí que un desborde de esta eminente atribución en desmedro de las facultades de los demás, revestiría la mayor gravedad para la armonía constitucional y el orden público El límite de la facultad de revisión judicial se encuentra ubicado en el ejercicio regular de las funciones privativas de los poderes políticos del Estado. En las causas en que se impugnan actos cumplidos por otros poderes en el ámbito de las facultades que les son privativas, la función jurisdiccional no alcanza al modo del ejercicio de tales atribuciones, en cuanto de otra manera se haría manifiesta la invasión del ámbito de las facultades propias de las otras autoridades de la Nación que se debe evitar (en similar sentido Fallos: 155-248; 254-45; 311-2580; 316-972; 320-2851; 321-1187; 322-1988; 324-2299; 326-417 del año 2003; entre muchos otros), lo cual significaría -reiterándolo expresado supra) una cuestión de la mayor gravedad para la armonía constitucional y el orden público (Fallos: 321-3226; 322-2370).

Declaró asimismo que si bien todo lo relativo al ejercicio de las facultades privativas de los órganos de gobierno queda -en principio- excluido de la revisión judicial (Fallos: 98-107; 165-199; 237-271; 307-1535; entre mucho otros), ello no obsta a que planteado un caso concreto -una causa en los términos del art. $116 \mathrm{CN}$ - se despliegue con todo vigor el ejercicio del control constitucional de la razonabilidad de las leyes y los actos administrativos, y una vez constatada su iniquidad manifiesta, corresponda declarar su inconstitucionalidad (en igual sentido ver Fallos: 325-28 del 1\%/2/2002)".

$Y$ de otro lado afirma que el Poder Judicial ejerce un verdadero control de constitucionalidad cuando verifica si los actos de los otros dos poderes se han cumplido dentro de sus respectivas esferas de actuación, lo cual exige un delicado ejercicio de interpretación constitucional y una responsabilidad de la Corte como último intérprete de la Constitución, que permite definir en qué medida el ejercicio de ese poder puede ser sometido a revisión judicial, "facultad esta última que sólo puede ser ejercida cuando haya mediado alguna violación normativa que ubique los actos de los otros poderes fuera de las atribuciones que la Constitución les confiere o del modo en que esta autoriza a ponerlas en práctica".

Asimismo sostuvo que la tradicional jurisprudencia del Tribunal postula que las razones de oportunidad, mérito, o conveniencia tenidas en cuenta por los otros poderes del Estado para adoptar decisiones que le son propias, no está sujetas al control judicial (cita a Fallos: 98-20; 147-402; 160-247; 238-60; 251-21; 275-218; 295-814; 303-1029; 3082246; entre muchos otros).

Pero estimamos preciso señalar aquí, que este último criterio no es absoluto, porque la propia CS ha establecido la excepción que hace procedente la revisibilidad judicial en 
estas cuestiones de oportunidad, mérito, o conveniencia, cuando los criterios adoptado por los otros Poderes resulten irrazonables, o sea, cuando los medios que arbitran no se adecuan a los fines cuya realización procuran, sean arbitrarios o irrazonables, o cuando consagran una manifiesta iniquidad (Fallos: 328-566 de 2005; 329-385 de 2006).

Planteada una causa, no hay otro poder por encima del de la Corte para resolver acerca de la existencia y los límites de las atribuciones constitucionales otorgadas a los departamentos legislativos, judicial y ejecutivo, y del deslinde de atribuciones de éstos entre sí y con respecto a los de las provincias, porque es inherente a las funciones de un tribunal de justicia, interpretar las normas que confieren las facultades privativas de los otros poderes, para determinar su alcance, sin que tal tema constituya una "cuestión política", inmune al ejercicio de la jurisdicción (Fallos: 324-3358).

\section{e. Algunos pronunciamientos paradigmáticos de la Corte Suprema sobre la justiciabi- lidad de las facultades privativas}

A partir de la variada plataforma argumental del alto Tribunal sobre la justiciabilidad que hemos expuesto precedentemente, se dictaron numerosas sentencias ante muy diversas situaciones institucionales, entre las cuales hemos escogido las que a continuación resumiremos:

\section{a) Sentencias de los Jurados de Enjuiciamiento de Jueces provinciales}

Reconociendo la potestad privativa de las provincias para la organización y el funcionamiento de los tribunales de enjuiciamiento para magistrados locales, en virtud de la autonomía provincial reconocida por la CN (arts. 5, 122 y concs.), la CS declaró que las sentencias de dichos tribunales configuran una "cuestión justiciable" y no constituyen en principio ámbitos vedados al conocimiento del Poder Judicial, no para resolver el conflicto de poderes, sino para hacer valer a favor de personas individuales la garantía federal de la defensa en juicio y del debido proceso ( "Graffigna Latino", Fallos: 308-961; asimismo entre muchos otros, en Fallos: 310-2845, "Magin Suárez"); 318-908; 329-3021 del año 2006; etc).

Esta doctrina está vigente hasta la actualidad, como lo pone de manifiesto la explícita y fundada sentencia dictada en el caso "Rojas Ricardo F.", del 7 de Octubre de 2008 (Fallos: 331-2195), en la que la CS afirmó que la competencia privativa y excluyente de la autoridad provincial para establecer el régimen de nombramiento y remoción de sus funcionarios deriva fundamentalmente de lo dispuesto por el artículo 122 de la CN, norma que excluye categóricamente la intervención del gobierno federal en la integración de los poderes locales; consecuentemente, la revisión de las decisiones adoptadas por los órganos de juzgamiento de magistrados y funcionarios establecidos en las constituciones provinciales fenece dentro del ámbito local de acuerdo con las normas que se hayan dictado al efecto, y sólo con carácter excepcional puede admitirse la intervención de la Corte cuando los planteos efectuados en el recurso extraordinario revelen en forma nítida, inequívoca y concluyente un grave menoscabo a las reglas del debido proceso que, asimismo, exhiba relevancia bastante para variar la suerte de la causa.

b) Sentencia de Jurados de Enjuiciamiento de Jueces Federales y resoluciones del Senado respecto de Jueces de la Corte Suprema de Justicia.

Con iguales fundamentos en el debido proceso y en la defensa en juicio, la CS declaró que tanto las sentencias del Jurado de Enjuiciamiento para los magistrados federales inferiores (v.g. caso "Brusa", Fallos: 326-4816 del año 2003; caso "Lona", Fallos: 327-46 del año 2004); como las resoluciones del Senado Nacional en los juicios políticos a los 

EN LA DOCTRINA DE LA CORTE SUPREMA DE JUSTICIA DE LA NACIÓN ARGENTINA

jueces de la propia Corte, v.g. caso "Moline O'Connor" (Fallos: 327-1914 del año 2004); caso "Boggiano" (Fallos 329-3235 del año 2006), eran revisables judicialmente al sólo efecto de examinar si se han violado o no, las garantías de la defensa en juicio y el debido proceso.

En "Moline O'Connor" el Tribunal sostuvo que al asignarle al Senado de la Nación una especial y limitada función judicial, le es exigible la observancia de reglas de procedimiento que preserven las garantías de defensa en juicio y del debido proceso que debe reconocerse a toda persona sometida a un juicio, no con el rigor que le es exigible a un tribunal penal, pero sí con la precisión y el cuidado que deje a salvo el efectivo derecho de defensa en juicio. La observancia de dichas reglas procesales, constituye materia revisable judicialmente para ejercer el control de validez constitucional de tales procedimientos, sin que ello implique el re-examen de las decisiones de fondo que puede dictar el cuerpo político por estar en la zona de exclusión donde residen las cuestiones políticas no justiciables.

\section{c) Respecto de Miembros del Ministerio Público}

En la sentencia recaída en la causa "Benitez, Omar Danilo" el 20 de Octubre de 2009 (Fallos: 332-2307), el Alto Tribunal afirmó que el recurso directo reglado por ante la Cámara Nacional de Apelaciones en lo Contencioso Administrativo Federal con respecto a las decisiones finales del Tribunal de Enjuiciamiento del Ministerio Público de la Nación (ley 24.946, art. 20, inc. $8^{\circ}$ ), representa una inequívoca definición por parte del Poder Legislativo de presentarse una cuestión contenciosa y justiciable por ante la justicia federal con arreglo a lo dispuesto en el art. 116 de la Ley Fundamental y en el art. 2 de la ley 27.

\section{d) Incorporación de legisladores al Congreso Nacional}

Un fallo realmente premonitorio en el que ya se atisbó la posibilidad de la justiciabilidad en este tópico, fue el dictado por la CS en 1998, en la causa "Prov. de Chaco" (Fallos: 321-3236) en el que paradójicamente rechazó dicha justiciabilidad por no darse los presupuestos de su procedencia. No obstante, el alto Tribunal reiteró que es inherente a las funciones de un tribunal judicial interpretar las normas que confieren las potestades que son privativas de los otros poderes para determinar su alcance, sin que tal tema constituya una "cuestión política" inmune al ejercicio de la jurisdicción (idem en Fallos: 322-2370). Si ante la impugnación del Partido Justicialista, el Senado actuó de modo que no excede el marco fijado por el art. 64 de la CN, ni se aparta en forma evidente de lo previsto en la cláusula transitoria cuarta de la Ley Fundamental, ni de las leyes que reglamentan su ejercicio, no resulta susceptible de revisión judicial el modo en que ese poder ha sido ejercido. (En igual sentido la CS se expidió en el caso "Haquim, Carlos G.", Fallos: 324-2299 de 2001).

A partir del año 2001 y por diversas circunstancias procesales, emitió en tres oportunidades pronunciamientos en el caso "Antonio Domingo Bussi" (Fallos: 324-3358; 326:4468 y 330:3160 el 13 de Julio de 2007), quien no obstante haber sido electo diputado nacional por la provincia de Tucumán, la Cámara de Diputados le negó su incorporación invocando inhabilidad moral y política e inidoneidad constitucional por su participación en la represión del Proceso Militar de 1976/83. Presentada la acción de amparo, y luego del embrollado trámite judicial con las consiguientes decisiones de la CS, atendiendo a las limitaciones que nos impone este estudio, sólo reseñaremos la doctrina que el alto Tribunal expuso en dichas oportunidades. 
Por una parte, sostuvo que configura cuestión justiciable el conflicto planteado por la negativa de la Cámara de Diputados a la incorporación de un legislador, con sustento en objeciones de orden ético derivadas de haber ocupado un cargo público durante el último gobierno de facto y en virtud de la atribución que le concede el art. $64 \mathrm{CN}$ respecto del examen y aprobación de los títulos de los legisladores, atribución no es exclusiva ni excluyente, en tanto el art. $116 \mathrm{CN}$ establece que incumbe al Poder Judicial el conocimiento y la decisión de todas las causas que versen sobre puntos regidos por ella.. Es función del Poder Judicial precisar el alcance de las normas jurídicas que atribuyen facultades a los poderes del Estado -en el caso el Congreso- pues dicha tarea exige una interpretación de la CN a fin de establecer si tales poderes existen y su ejercicio puede someterse a revisión judicial.

Por otra parte señaló que, planteada una causa, no hay otro poder por encima de esta Corte, para resolver acerca de la existencia y los límites de las atribuciones constitucionales otorgadas a los Departamentos Legislativo o Ejecutivo, y del deslinde de atribuciones de éstos entre sí y con respecto a las provincias, sin que tal tema constituya una "cuestión política", inmune al ejercicio de la jurisdicción atendiendo a que el Tribunal es el intérprete final de la Constitución (doctrina de Fallos: 316-972).

Finalmente afirmó que una interpretación que llevara al extremo la no justiciabilidad de las decisiones del Congreso, anularía el diálogo de poderes que la CN sustenta, y podría producir el desamparo de los ciudadanos que pertenecen a minorías, al quedar sujetos a lo que decidieran mayorías circunstanciales.

Esta doctrina ya había sido ratificada en el año 2003 en la causa "Alianza Frente por un Nuevo País" (Fallos: 326-1816), en la que se controvertía la pertenencia de una banca de senador nacional y, posteriormente, fue reiterada el 8 de abril de 2008 en el caso "Patti, Luis A." (Fallos, 331:548), haciendo lugar al amparo que el actor, en su condición de diputado electo, promovió contra la resolución de la Cámara de Diputados que rechazó su incorporación como miembro del Cuerpo.

e) Trámite de la formación y sanción de las leyes en el Congreso

En el caso "Nobleza Picardo" (Fallos: 321-3487 de 1998), el alto Tribunal afirmó que corresponde a la Corte intervenir en lo atinente al proceso de formación y sanción de las leyes, cuando al no haber sido aprobado un proyecto por ambas Cámaras del Congreso, se lo pasa al Poder Ejecutivo para su examen y promulgación, sin observar el art. 78 de la CN.

Tiempo después en el caso "Famyl S.A." (Fallos: 323-2256 de 2000), la CS sostuvo que si bien lo relativo al proceso de formación y sanción de las leyes, al constituir una atribución constitucional privativa de los Poderes Legislativo y Ejecutivo (arts. 77 a 84 $\mathrm{CN}$ ), resultan por regla general, ajenas a las facultades jurisdiccionales de los tribunales, ello reconoce excepción en los supuestos en que se ha demostrado fehacientemente la falta de concurrencia de los requisitos mínimos e indispensables que condicionan la creación de la ley.

f) Veto del P.E. respecto de proyectos sancionados por el Congreso

Esta facultad privativa del Presidente (art. $83 \mathrm{CN}$ ) fue declarada revisable jurisdiccionalmente en el caso "Colella" (Fallos: 268-352 de 1967), sosteniendo la CS que la doctrina de la irrevisibilidad y de las "cuestiones políticas", no es aplicable al veto, pues "existe cuestión justiciable cuando se cuestiona la falta de promulgación válida de la ley", como 
en el caso de autos en que se le negó al PE la facultad de promulgar sólo la parte no vetada del proyecto del Congreso, por afectar la unidad inescindible de la ley. (En igual sentido, Fallos: 318-445; 319.1479; 323-2256 de 2000).

\section{g) Acuerdos del Senado para nombramientos por el Poder Ejecutivo}

Con motivo de un acuerdo denegado por el Senado de la Nación para el ascenso de un oficial de la armada sin la mayoría absoluta que exige el reglamento, se originó el caso "Binotti" (Fallos: 330-2222 de 2007) en el que la CS declaró que ningún departamento de gobierno puede ejercer lícitamente otras facultades que las que le han sido otorgadas (Fallos: 137-47) y es del resorte de esta Corte juzgar la existencia y límites de las facultades privativas de los otros poderes (fallos: 210-1095) y la excedencia de las atribuciones en la que éstos puedan incurrir (Fallos: 254-43), ya que es "cuestión justiciable" determinar si una Cámara del Congreso ha actuado, o no, dentro de su competencia (Fallos: 324-3358). Habiendo el Senado de la Nación violado los preceptos reglamentarios federales y lesionando derechos individuales, circunstancias que no podrían quedar exentas del control de los magistrados de la República, se resolvió declarar la nulidad de la votación de la Cámara de Senadores solicitada por el actor.

En este mismo tópico, mediante el fallo de fecha 21 de abril 2015 recaído en los autos "Aparicio, Ana Beatriz y otros c/ Estado Nacional -CSJN- Consejo de la Magistratura arto $110 \mathrm{~s} /$ empleo público", la CSJN decidió declarar la nulidad de la designación de conjueces efectuada por el PEN mediante el decreto 856/14, en tanto el acuerdo no contó con el voto de los dos tercios de los miembros presentes del Senado de la Nación, en sesión pública convocada a tal efecto, como exige el artículo 99, inc. $4^{\circ}$, primer párrafo de la CN y, además, violando asimismo la reglamentación del art. 22 del Dto-ley 1285/58 -ratificado por la ley 14.467 y sus modificatorias- cuando en lo pertinente dispone que "los conjueces de la Corte Suprema de Justicia de la Nación, en número de diez (10), serán designados por el Poder Ejecutivo con acuerdo del Senado".

Entre otros rigurosos fundamentos, la Corte señaló que el nombramiento de los jueces de la Nación con arreglo al procedimiento constitucionalmente establecido, se erige en uno de los pilares esenciales del sistema de división de poderes sobre el que se asienta la República, ya que las citadas disposiciones responde a la necesidad de afirmar la independencia e imparcialidad de los jueces en beneficio exclusivo de los justiciables.

Que las previsiones del referido art. 99 , inciso $4^{\circ}$ se relacionan -en última instancia- con la garantía del juez natural, ya que toda persona cuya causa deba ser decidida por abogados que no integran el órgano judicial, tiene derecho a que quienes conozcan sobre su litigio hayan sido designados de conformidad con los mecanismos que el constituyente adoptó en garantía de la independencia e imparcialidad del órgano judicial.

\section{h) La revisibilidad judicial del procedimiento y normas de una Reforma Constitucional}

En este tema de indudable gravedad institucional referido al control jurisdiccional de las facultades privativas de las convenciones reformadoras en ejercicio del poder constituyente derivado, existieron diversos casos que fueron marcando los caminos hacia la posibilidad de la revisibilidad judicial, entre los cuales podemos señalar los siguientes con amplios desarrollos doctrinales que nos vemos obligados a resumir.

a) El caso "Ríos" (Fallos: 316-2743 de 1993), en el que la CS afirmó que los poderes conferidos a la Convención Constituyente de la Provincia de Corrientes, no pueden reputarse ilimitados, porque el ámbito de aquéllos se haya circunscripto por los términos de la norma que la convoca y le atribuye competencia.

b) En la causa "Iribarren" (Fallos: 322-1253 de 1999) declaró la inconstitucionalidad del 
art. 88 de la Constitución de la Provincia de Santa Fe, pues al hacer cesar la inamovilidad de los jueces al alcanzar la edad requerida para obtener la jubilación ordinaria, los somete a una situación de marcada precariedad en el ejercicio de sus funciones sujeta al arbitrio de otro poder del Estado provincial, circunstancia que afecta la independencia de los jueces que hace a la esencia del régimen republicano.

Finalmente y otorgando rotundidad a la revisibilidad que venía sosteniendo respecto de las convenciones y los textos constitucionales provinciales, la CS se pronunció categóricamente respecto del ámbito federal, en el célebre caso "Fayt, Carlos S." (Fallos: 322-1616 de 1999) que tuvo origen cuando el actor, que se desempeñaba como juez del alto Tribunal, invocando diversas razones, planteó la nulidad de la reforma constitucional introducida en 1994 en cuanto disponía que un nuevo nombramiento precedido de acuerdo del Senado, sería indispensable para continuar en el cargo a cualquier juez que cumpla los 75 años, prescripción que hace a la garantía de la inamovilidad de los jueces y que no había sido mencionada en la declaración de necesidad de la reforma formulada por el Congreso Nacional y que es la que fija el ámbito de la competencia de la Convención.

La CS en extensa sentencia hizo lugar a la demanda, afirmando en la breve síntesis que formulamos, los siguientes fundamentos:

a) Que se declara revisible jurisdiccionalmente no sólo el aspecto procedimental, sino también el aspecto sustancial o contenido de la reforma constitucional, para juzgar en los casos planteados si el acto impugnado ha sido expedido por el órgano competente, dentro del marco de sus atribuciones y con arreglo a las formalidad a que está sujeto;

b) No hay otro poder por encima de esta Corte para resolver, como intérprete final de la $\mathrm{CN}$, acerca de la existencia y de los límites de las atribuciones constitucionalmente otorgadas a los otros poderes sin excepción alguna en estos ámbitos;

c) Procede el control sobre el alcance de disposiciones y derogaciones adoptadas por la Convención reformadora, privando de efecto a aquellas realizadas en infracción a los límites impuestos al poder reformador;

d) El Congreso de la Nación ha aceptado el carácter justiciable de los límites del poder reformador, al prever la sanción de nulidad de "las modificaciones, derogaciones y agregados" que realice la Convención apartándose de la competencia establecida (art. 6 de la ley 24.309);

e) Dado que ni en los artículos 2 y 3 de la ley 24.309, ni en el "Núcleo de Coincidencias Básicas", se ha incluido la posibilidad de reformar la norma constitucional relativa a la garantía de la inamovilidad de los magistrados, cabe considerar nula la reforma introducida por la Convención Reformadora de 1994 al art. 99, inc. 4, párr. 3 de la CN, ya que la alteración que la misma comportó a dicha garantía a partir del cumplimiento de una edad determinada, no reconoce habilitación suficiente en las facultades implícitas que se derivan de la expresa atribución otorgada a la Convención para reformar el régimen de designación, ni jamás puede entenderse como implicada en la mera actualización o adecuación de las facultades del Poder Ejecutivo.

Casi dos décadas después, la CS se apartó de la jurisprudencia in re "Fayt" y la modificó restrictivamente en grado sumo en la causa "Schiffrin, Leopoldo Héctor c/ Poder Ejecutivo Nacional s/ acción meramente declarativa", del 28 de marzo de 2017 (Fallos: 340-257), en cuyo fallo y con el voto mayoritario de los jueces Lorenzetti, Maqueda y Rosatti, y la disidencia del juez Rosenkrantz, se pronunció de modo contrario a la anterior doctrina. La mencionada causa llegó en apelación extraordinaria con motivo que 
la Cámara Federal de La Plata rechazó el recurso de apelación deducido por el Estado Nacional y confirmó la sentencia de primera instancia que había hecho lugar a la demanda interpuesta por el juez Schiffrin "declarando la nulidad e inaplicabilidad" del tercer párrafo introducido por la Convención Reformadora de 1994 en el art. 99, inc. $4^{\circ}$ (antes art. 86 inc. $5^{\circ}$ ) de la Constitución Nacional.

Este nuevo criterio era previsible, a poco que se repare que de los tres votos de la mayoría, dos corresponden a los señores Jueces Maqueda y Rosatti que se habían desempeñado como convencionales constituyentes en la Reforma de 1994 en que se sancionó la norma ahora impugnada. Dada esta circunstancia, entendemos que no correspondía que fueran ellos quienes ahora juzgaban la validez de la norma de la que precisamente fueron autores constituyentes. En consecuencia, debieron apartarse del conocimiento de la causa.

Como en casos anteriores, aquí también nos vemos limitados a resumir los conceptos cardinales de la extensa fundamentación del pronunciamiento, en el que la CS afirmó:

a) Si la declaración de inconstitucionalidad de un acto de los poderes constituidos ya presenta suma gravedad institucional y debe ser considerada como ultima ratio del ordenamiento jurídico (Fallos: 300:241, 1087; 302:457, 484, 1149; entre otros), con mucha mayor rigurosidad debe serlo cuando se ha puesto en cuestión la validez de una norma de la Constitución sancionada por una Convención Reformadora elegida por el pueblo.

b) No corresponde aplicar un criterio de interpretación restrictivo -como el que se desprende del caso "Fayt"- de manera de limitar severamente la soberanía de la Convención, sino amplio y extensivo respecto de las facultades de la Convención Constituyente (art. $30 \mathrm{CN}$ ), de modo que en caso de duda, debe juzgarse a favor de la plenitud de sus poderes, y solo cabría des calificar la actividad del órgano Constituyente en dos supuestos: cuando se demuestre categóricamente una grave, ostensible y concluyente discordancia sustancial que haga absolutamente incompatible la habilitación conferida por el Congreso de la Nación y la actuación llevada a cabo por la Convención Constituyente; o, cuando lo decidido por la Convención afectara, de un modo sustantivo y grave, el sistema republicano o los derechos fundamentales inderogables que forman parte del contenido pétreo de la Constitución.

c) La interpretación estricta, significa que la Convención no puede apartarse de la necesidad y de los contenidos fijados por el Congreso, porque acarrea la nulidad, criterio hermenéutico que no puede sostenerse porque limita el poder constituyente de la Convención. Por ello, se torna necesario abandonar la doctrina del caso "Fayt", y adoptar un nuevo estándar de control, deferente y respetuoso de la voluntad soberana del pueblo expresada por la Convención en las disposiciones que aprobare, pero que, a su vez, preserve en cabeza del Departamento Judicial la atribución para revisar dichas cláusulas y, como ultima ratio de la más marcada rigurosidad, descalificarlas.

d) Tras la habilitación otorgada a la Convención Constituyente por la ley 24.309 (art. $3^{\circ}$, punto e), la intervención de los Poderes Ejecutivo y Legislativo -cuando los jueces federales alcanzan la edad de 75 años- aparece razonablemente como una de las modalidades posibles reservadas al constituyente para hacer efectiva esa competencia, por lo cual, la Convención no ha excedido los límites de la norma habilitante al incorporar la cláusula del art. 99, inc. $4^{\circ}$, 3er. párr. de la CN, ni tampoco ha vulnerado el principio de 
independencia judicial, esencial a la forma republicana de gobierno, en tanto el límite de edad modifica únicamente el carácter vitalicio del cargo pero no la garantía de inamovilidad.

BIBLIOGRAFÍA

- BIANCHI, Alberto "Control de Constitucionalidad", Edit. Ábaco, Bs. As. 1992

- BIDART CAMPOS, Germán, Tratado Elemental de Derecho Constitucional Argentino, Ediar, Buenos Aires, 1993.

- BIDART CAMPOS, Germán, "Derecho Constitucional del Poder", Ediar 1967, T. II .

- BIDEGAIN, Carlos María, "Cuadernos de Derecho Constitucional", Buenos Aires, 1975, T. I - 127 a 139.

- EKMEKDJIAN, Miguel Angel "Tratado de Derecho Constitucional", Depalma, Bs. As. 1995, T. III, 2004.

- GONZALEZ, Joaquín Manual de la Constitución Argentina", Edit. Estrada, 1951

- GONZÁlEZ CALDERÓN, Juan "Curso de Derecho Constitucional", Edit. Kraft 1960.

- HARO, Ricardo, Control de Constitucionalidad, Editorial Zavalía, Buenos Aires, 2008.

- LINARES QUINTANA, Segundo V. "Derecho Constitucional e Instituciones Políticas", Plus Ultra 1981.

- MARIENHOFF, Miguel S. "Tratado de Derecho Administrativo", Abeledo Perrot, 1966, T. II .

- RAMELLA Pablo A, "Derecho Constitucional", Depalma, 1982.

- ROMERO, Cesar Enrique "Derecho Constitucional", Edit. Zavalía, 1975.

- SAGÜES, Néstor P., "Recurso Extraordinario", Depalma, 1984, T. I -

- QUIROGA LAVIÉ, Humberto "Derecho Constitucional", Cooperadora de Derecho, Buenos Aires

• VANOSSI, Jorge R. "Teoría Constitucional", Depalma 1976, T.II - 177/211. 